\title{
Improving the undiagnosed rate of diabetes mellitus using a point-of-care AIC device
}

\begin{abstract}
Aim: To determine the undiagnosed rate of diabetes and prediabetes in a high-risk rural population. Over $8 \%$ of the American population has diabetes mellitus. Portions of the country with the greatest prevalence include rural, underserved areas in the South. Despite its wide-spread prevalence 7 million are unknowingly living with the condition. Early detection allows for prevention of long-term disease complications.
\end{abstract}

Methods: Patients at a rural family medicine clinic were prospectively pre-evaluated according to the American Diabetes Association's criteria. Eligible adults were offered free point-of-care hemoglobin HbA1c screening.

Results: Sixty-one percent $(\mathrm{n}=69)$ were unknowingly living with chronic hyperglycemia; $50 \%(\mathrm{n}=57)$ had an $\mathrm{HbA1c}$ between $5.7 \%$ and $6.4 \%$. Average $\mathrm{HbA1c}$ values for patients with euglycemia, prediabetes, and diabetes were $5.34 \%, 5.91 \%$, and $6.88 \%$, respectively. Body mass index $(\mathrm{p}=0.001)$ and age $(\mathrm{p}=0.0003)$ were statistically significant contributors to $\mathrm{HbAlc}$.

Conclusion: Systematically screening asymptomatic adults for diabetes is important. Using a convenient point-of-careHbAlc device facilitated diagnosis and further articulated the incidence of diabetes and prediabetes in a rural underserved population. In turn, early diagnosis and intervention allows patients to incorporate daily healthy behavioral strategies which can delay the diagnosis or slow the progress of diabetes and ultimately improve morbidity and mortality.

Keywords: diabetes mellitus, point-of-care, hemoglobin a1c, diagnosis, prediabetes, undiagnosed, incidence
Volume 2 Issue I - 2015

\author{
Heather PWhitley, ' Courtney Hanson, ${ }^{2}$ \\ Jason M Parton ${ }^{3}$ \\ 'Department of Pharmacy Practice, Auburn University Harrison \\ School of Pharmacy, USA \\ ${ }^{2}$ Department of Information Systems, The University of Alabama, \\ USA \\ ${ }^{3}$ Department of Information Systems, The University of Alabama, \\ USA
}

\begin{abstract}
Correspondence: Heather PWhitley, Associate Clinical Professor of Pharmacy Practice, Department of Pharmacy Practice, Baptist Health, Montgomery Family Medicine Residency Program, 437I Narrow Lane Rd, Suite \#100 Montgomery, Alabama 36I I6, USA, Tel 334-280-7084, Fax 334613-3685, Email whitlhp@auburn.edu
\end{abstract}

Received: December 19, 2014 | Published: January 08, 2015
Abbreviations: EMR, electronic medical record; CDC, centers for disease control and prevention; POC, point-of-care; BMI, body mass index; HbA1c, hemoglobin A1C; ANCOVA, analysis of covariance

\section{Introduction}

According to 2014 estimates by the Centers for Disease Control and Prevention (CDC) 29.1million Americans or 9.3\% of the population have diabetes. ${ }^{1}$ While many (21million) are aware of their diagnosis, a surprising 8.1 million are unknowingly living with the condition. Similarly, 37\%(86million) of Americans have prediabetes, ${ }^{1}$ however, approximately only $11 \%{ }^{2}$ of these individuals are aware of their status.

Portions of the country with the greatest prevalence of diabetes include rural, underserved areas in the South. ${ }^{3,4}$ Alabama exceeds the national average with more than $11 \%$ of its population living with diabetes. ${ }^{5}$ A rural geographical region, known as the Black Belt Counties of Alabama, are at even greater disadvantages with the prevalence of diabetes in some counties approaching $20 \%{ }^{6}$ It is further estimated that only $7 \%$ of the Alabama population has ever been informed they have prediabetes. ${ }^{5}$

Consequences of unawareness are unfortunate; uncontrolled chronically elevated blood glucose results in permanent organ damage. Diabetes is the seventh leading cause of death in America. ${ }^{1}$ Those with diabetes are 1.7times more likely to die from heart disease and 1.8times more likely to be hospitalized for a stroke compared to adults without the disease. It is also the primary cause of kidney failure, leads to retinopathy, and results in $60 \%$ of non- traumatic lower-limb amputations. In addition to the high mortality and morbidity associated with diabetes, it is also costly. Nationally, diabetes costs \$245billion each year; including \$ 176billion in direct and \$ 69billion in indirect costs. Those with diabetes have healthcare costs 2.3times higher than those without the diagnosis. ${ }^{1}$

Early detection of the disease may allow individuals to prevent or delay the development of chronic hyperglycemic-induced complications, ${ }^{7}$ and thus significantly lower the economic burden of diabetes on society. Patients with knowledge of prediabetes could facilitate the implementation of behavioral alterations which could ultimately delay or prevent the development of diabetes. ${ }^{8}$ Regardless of the diagnosis of diabetes or prediabetes, simple awareness remains an obstacle to disease state management and prevention across the country and especially in rural Alabama.

To help facilitate early detection and lower the undiagnosed rate, free hemoglobin A1C (HbA1c) point-of-care (POC) screenings were offered to patients at a rural family medicine practice located in Hale County Alabama. The purpose was to determine the rate of diabetes and prediabetes in adult patients unknowingly living in a chronic state of hyperglycemia in a geographically high-risk population. This manuscript reports data collected over a 6month period (April - October 2013).

\section{Methods}

This prospective study was approved by an Institutional Review Board via expedited status and was funded by the Diabetes Hands Foundation. All patients scheduled for physician or nurse practitioner 
appointments on Tuesdays at a privately operated family medicine rural clinic in Hale County Alabama were systematically evaluated the day before using the electronic medical record (EMR). Patient's chief complaint for the scheduled medical appointment ranged from chronic to acute concerns but had no bearing on enrollment in the study. Patients of age 45years or older were included. Exclusion criteria included pre-existing diagnosis of diabetes mellitus, oral or parenteral steroid use in the past 3months, current pregnancy, or receiving an $\mathrm{HbAlc}$ test (POC or venipuncture) in the past year.

Those meeting study criteria were then approached in clinic during their scheduled medical visit by a clinical pharmacist to confirm accuracy of eligibility. Patients confirming lack of steroid use in the past 3 months, prior HbAlc test in the past 12 months, and current diabetes diagnosis were offered a free-of-charge POC $\mathrm{HbAlc}$ test using the Bayer A1C Now+(A1C Now + , Bayer Diabetes Care, Whippany, NJ). Patients not approached, due to missing their medical appointment or inability of the clinical pharmacist to offer participation, were categorized as "unable to offer."

During the 5minutes required for processing blood samples by the HbA1c POC device patients were asked additional follow-up questions by the clinical pharmacist. Answers to these questions further described the analyzed population in terms of concomitant disease states, presence of hyperglycemic symptoms, and previous healthcare provider recommended behavioral modifications.

Table I Analysis of Covariance and Adjusted Means

\begin{tabular}{lllll}
\hline Variable & Estimate & Standard Error & t value & p-value \\
\hline Race/Ethnicity & 0.126 & 0.208 & 0.61 & 0.55 \\
Sex & $0.06 \mathrm{I}$ & 0.094 & 0.65 & 0.52 \\
Age $($ years $)$ & 0.018 & 0.004 & 3.75 & 0.0003 \\
BMI $\left(\mathrm{kg} / \mathrm{m}^{2}\right)$ & 0.025 & 0.007 & 3.38 & $0.00 \mathrm{I}$ \\
Adjusted means & & & & \\
Race/Ethnicity & African American & 5.9 & & \\
& Caucasian & 5.77 & & \\
Sex & Female & 5.87 & & \\
& Male & 5.81 & & \\
\hline
\end{tabular}

\section{Results}

From April through October 2013the EMR of 475 patients were systematically pre-evaluated for inclusion. Approximately half $(n=245 ; 51.6 \%)$ were excluded, predominately for age $(n=141)$, current diagnosis of diabetes $(n=75)$, or HbA1c test in the past 12 months $(n=68)$. An additional 85 patients were not offered the opportunity to participate in the study due to missed appointments or conflicts with the clinical pharmacist's schedule. During the initial patient interview 19 were further excluded for recent steroid use. A total of 126 patients were offered the opportunity to participate; 12 declined and 114 consented and were provided the free POC $\mathrm{HbA} 1$ cscreening test and evaluation. One patient's data was excluded due to the POC device's inability to accurately calculate the blood sample; thus 113 samples were analyzed (Figure 1).

Baseline demographics showed those included in the study ranged in age from 45 to 91 (mean 62.6) years. The majority was Caucasian $(93 \%, n=106)$ with more females $(58 \%, n=66)$ than males. On average, the study population was obese with an average height, weight, and further summarized in Table 2.
Each patient and healthcare provider was informed of the HbA1cresult immediately after testing. Test outcomes were entered into each patient's EMR. HbA1c results of $6.5 \%$ or greater prompted healthcare providers to address the concern during the scheduled medical visit. Patients with $\mathrm{HbA1c}$ results between $5.7 \%$ and $6.4 \%$ were provided a prediabetes brochure which provided basic education and information about local resources. Flags were further placed in the EMR prompting medical personnel to re-screen prediabetic individuals for diabetes in one years' time. Patients with an HbAlcresult of 5.7\% or greater were additionally offered free clinical pharmacy visits to address hyperglycemic concerns.

\section{Data collection}

Data were prospectively documented on a pre-designed TeleForm collection tool (TeleForm v10, Cardiff Software, Brookline, MA) and were scanned using TeleForm software. Data were exported into Microsoft Excel for analysis.

\section{Statistical analysis}

Sample characteristics were assessed using frequencies and/ or averages for variables in the study. Descriptive statistics were used to identify potential patterns or disparities among factors for $\mathrm{HbA} 1$ coutcomes. An analysis of covariance (ANCOVA) was performed to examine differences of patients' $\mathrm{HbA1c}$ by sex and race while adjustments were made for age and body mass index (Table 1).

body mass index (BMI) of 1.71 meters, $92.49 \mathrm{~kg}$, and $31.3 \mathrm{~kg} / \mathrm{m}^{2}$, respectively. Descriptive statistics for the sample population are

Results revealed that $61 \%(\mathrm{n}=69)$ of patients had an $\mathrm{HbA} 1 \mathrm{c} \geq 5.7 \%$ and $11 \%(n=12)$ had an $\mathrm{HbA} 1 \mathrm{c} \geq 6.5 \%$. Fifty percent $(\mathrm{n}=57)$ had an $\mathrm{HbA} 1 \mathrm{c}$ in the prediabetes range of $5.7 \%$ to $6.4 \%$. Only $39 \%(\mathrm{n}=44)$ of patients had an $\mathrm{HbA} 1 \mathrm{c} \leq 5.6 \%$. The average $\mathrm{HbA} 1 \mathrm{c}$ values for patients with euglycemia, prediabetes, and diabetes were $5.34 \%, 5.91 \%$, and $6.88 \%$, respectively. When considering patients' history, those that reported having been advised to lose weight were found to have lower HbA1c outcomes $(4.78 \%)$ compared to patients never advised to lose weight $(5.80 \%)$. While mean $\mathrm{HbAlc}$ measured slightly higher when certain symptoms were present (e.g. dry mouth), no single hyperglycemic symptom had a strong association with $\mathrm{HbA1c}$ results. (Table 3) Not surprisingly, the significant factors of the model were $\mathrm{BMI}(\mathrm{p}=0.001)$ and age $(\mathrm{p}=0.0003)$. If all other factors remained static, for each $1 \mathrm{~kg} / \mathrm{m}^{2}$ increase in BMI or year increase in age, HbA1c was estimated to increase by $0.025 \%$ or $0.018 \%$, respectively. 


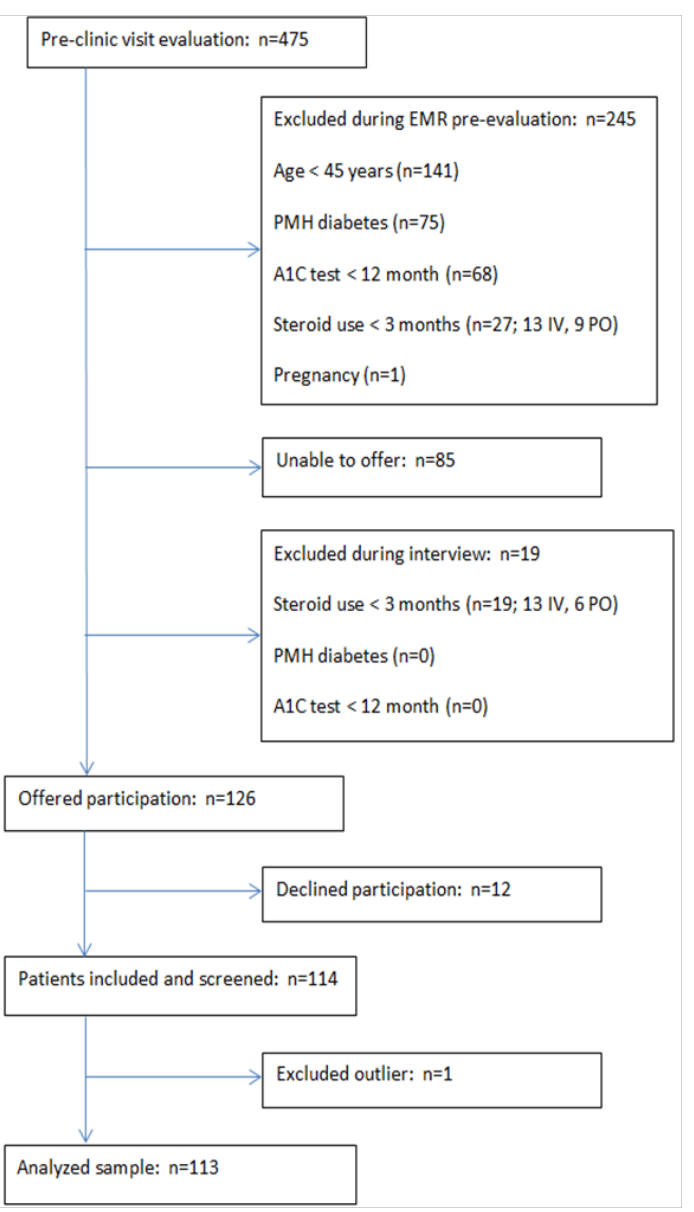

Figure I Consort Diagram for Screening and Enrollment.

Table 2 Sample Demographics and HbAIc Results $(n=1 \mid 3)$

\begin{tabular}{|c|c|c|c|}
\hline Characteristic & $\mathbf{N}(\%)$ & Mean & Std. Dev. \\
\hline Age (years) & & 62.6 & 10.3 \\
\hline BMI $\left(k g / m^{2}\right)$ & & 31.4 & 7.15 \\
\hline Morbidly Obese (BMI>40) & $12(I I)$ & 46.4 & 5.11 \\
\hline Obese (BMI 30-40) & $46(4 I)$ & 34.1 & 2.4 \\
\hline Overweight (BMI 25-29) & $38(33)$ & 27.6 & 1.45 \\
\hline Healthy Weight (BMI I8.5-24) & $17(15)$ & 22.2 & 2.29 \\
\hline \multicolumn{4}{|l|}{ Race/Ethnicity } \\
\hline African American & $7(6)$ & & \\
\hline Caucasian & $106(93)$ & & \\
\hline \multicolumn{4}{|l|}{ Sex } \\
\hline Female & $66(58)$ & & \\
\hline Possesses Health Insurance & 107(95) & & \\
\hline AIC Results (\%) & 113 & 5.79 & 0.53 \\
\hline Diabetes (AIC $\geq 6.5 \%$ ) & $12(11)$ & 6.88 & 0.52 \\
\hline Prediabetes (AIC 5.7-6.4\%) & $57(50)$ & 5.91 & 0.19 \\
\hline Healthy (AIC $\leq 5.6 \%$ ) & $44(39)$ & 5.34 & 0.24 \\
\hline
\end{tabular}

Table 3 Sample HbAlc Measurements Regarding Patient Characteristics and Hyperglycemic Conditions

\begin{tabular}{|c|c|c|c|c|}
\hline Variable & & $N(\%)$ & $\begin{array}{l}\text { Mean } \\
\text { HbAlc }\end{array}$ & Std. Dev \\
\hline \multirow{2}{*}{ Ethnicity } & $\begin{array}{l}\text { African } \\
\text { American }\end{array}$ & $7(6)$ & 6.2 & 0.59 \\
\hline & Caucasian & $106(94)$ & 5.85 & 1.03 \\
\hline \multirow{2}{*}{ Sex } & Female & $66(58)$ & 5.98 & 1.27 \\
\hline & Male & $47(42)$ & 5.72 & 0.4 \\
\hline \multirow{2}{*}{$\begin{array}{l}\text { Advised to } \\
\text { change diet }\end{array}$} & Yes & $48(42)$ & 5.79 & 0.65 \\
\hline & No & $65(58)$ & 5.79 & 0.43 \\
\hline \multirow{2}{*}{$\begin{array}{l}\text { Advised to } \\
\text { exercise more }\end{array}$} & Yes & $59(52)$ & 5.94 & 1.34 \\
\hline & No & $54(48)$ & 5.79 & $0.4 I$ \\
\hline \multirow{2}{*}{$\begin{array}{l}\text { Advised to lose } \\
\text { weight }\end{array}$} & Yes & $45(40)$ & 4.78 & 0.68 \\
\hline & No & $68(60)$ & 5.8 & $0.4 I$ \\
\hline \multirow{2}{*}{$\begin{array}{l}\text { History of high } \\
\text { cholesterol }\end{array}$} & Yes & $66(58)$ & 5.77 & 0.58 \\
\hline & No & $47(42)$ & 5.82 & 0.47 \\
\hline \multirow{2}{*}{$\begin{array}{l}\text { History of high } \\
\text { blood pressure }\end{array}$} & Yes & $64(57)$ & 5.82 & 0.45 \\
\hline & No & $49(43)$ & 5.76 & 0.45 \\
\hline \multirow{2}{*}{$\begin{array}{l}\text { History of } \\
\text { gestational } \\
\text { diabetes }\end{array}$} & Yes & $2(2)$ & 6.1 & 0.71 \\
\hline & No & III(98) & 5.78 & 0.53 \\
\hline \multirow{2}{*}{$\begin{array}{l}\text { History of } \\
\text { prediabetes }\end{array}$} & Yes & $6(5)$ & 5.73 & 0.58 \\
\hline & No & $107(95)$ & 5.79 & 0.53 \\
\hline \multirow{2}{*}{ Blurred vision } & Yes & $13(12)$ & 5.86 & 0.78 \\
\hline & No & $100(88)$ & 5.78 & 0.5 \\
\hline \multirow{2}{*}{$\begin{array}{l}\text { Difficulty } \\
\text { concentrating }\end{array}$} & Yes & $17(15)$ & 5.87 & 0.92 \\
\hline & No & $96(85)$ & 5.78 & 0.44 \\
\hline \multirow{2}{*}{ Dry mouth } & Yes & $29(26)$ & 5.89 & 0.62 \\
\hline & No & $84(74)$ & 5.76 & 0.5 \\
\hline \multirow{2}{*}{$\begin{array}{l}\text { Feeling tired or } \\
\text { weak }\end{array}$} & Yes & $49(43)$ & 5.81 & 0.6 \\
\hline & No & $64(57)$ & 5.78 & 0.48 \\
\hline \multirow{2}{*}{$\begin{array}{l}\text { Frequent } \\
\text { urination }\end{array}$} & Yes & $23(20)$ & 5.79 & 0.49 \\
\hline & No & $90(80)$ & 5.79 & 0.55 \\
\hline \multirow{2}{*}{ Headaches } & Yes & $23(20)$ & 5.8 & 0.78 \\
\hline & No & $90(90)$ & 5.79 & 0.45 \\
\hline \multirow{2}{*}{ Leg cramps } & Yes & $4 I(36)$ & 5.77 & 0.57 \\
\hline & No & $72(64)$ & 5.8 & 0.52 \\
\hline \multirow{2}{*}{ Thirst } & Yes & $19(17)$ & 5.82 & 0.75 \\
\hline & No & $94(83)$ & 5.78 & 0.48 \\
\hline \multirow{2}{*}{ Weight loss } & Yes & $16(14)$ & 5.54 & $0.4 I$ \\
\hline & No & $97(86)$ & 5.83 & 0.54 \\
\hline
\end{tabular}




\section{Discussion}

The sample studied was representative of the general population in this geographic region regarding prevalence of diabetes. Of the 475 medical charts accessed 75 patients had diabetes, indicating a $15.8 \%$ prevalence of diagnosed disease, which closely compares to CDC 2011 estimates for Hale County of $14.9 \%{ }^{9}$

The study showed a surprisingly large number of rural Alabama residents $(61 \%, \mathrm{n}=69)$ unknowingly living in a chronic state of hyperglycemia $(\mathrm{HbA} 1 \mathrm{c} \geq 5.7 \%)$ be it prediabetes $(50 \%, \mathrm{n}=57)$ or diabetes $(11 \%, \mathrm{n}=12)$. Not surprisingly, BMI $(\mathrm{p}=0.001)$ and age $(p=0.0003)$ were statistically significant factors found to impact the model. When analyzed for covariance, $\mathrm{HbAlc}$ was found to increase by $0.028 \%$ for each $1 \mathrm{~kg} / \mathrm{m}^{2}$ increase in BMI and by $0.018 \%$ for each annual increase in age. These variables may influence the development of diabetes in all areas; however, culture and lifestyle seen in rural Alabama, which often include calorie-rich meals and less frequent forms of physical activity, may have a more profound impact. ${ }^{10}$ Indeed, CDC data indicate the densest national region for diabetes to be the Southeastern portion. ${ }^{6}$ Therefore, areas such as rural Alabama, where the prevalence is known and now demonstrated at a local level to be particularly high, should gain attention as targeted regions in need of efforts to diagnose, slow progression of, and prevent diabetes.

This study screened patients 45years of age or older per the ADA recommendation, which would include both symptomatic and asymptomatic individuals. In fact, when specifically asked, 73\% reported the presence of hyperglycemic symptoms. However, no single or combination of hyperglycemic symptom(s) correlated specifically with HbAlc. The most commonly occurring hyperglycemic symptoms were ambiguous: feeling tired or weak $(43 \%, \mathrm{n}=49)$ and leg cramps $(36 \%, n=41)$, rather than cardinal polyuria $(20 \%, n=23)$ and polydipsia $(17 \%, \mathrm{n}=19)$ symptoms. Collectively the data emphasize the importance of proactively screening eligible individuals regardless of presence of symptoms.

The American Heart Association and American Diabetes Association have both called for new strategies to improve screening and detection of diabetes and prediabetes. In fact, the newly released "Healthy People 2020" rates screening for diabetes as one of the healthcare system's top needed measures. ${ }^{11}$ Practically, simple criteria for screening any disease are necessary when clinically applied. This investigation proved that implementation of screening strategies according to the American Diabetes Association's age recommendation using a POC HbAlc device enhances identification of those with and at-risk for developing diabetes. Advantages of the HbAlctest include the result reflecting long-term glycemic control and lack of fasting requirement versus a point-in-time glucose assessment with a FPG or required 2hour time-point following an OGTT. ${ }^{12,13}$ Additionally, the $\mathrm{HbAlc}$ test has improved test-retest reliability and greater preanalytical stability. ${ }^{14}$ Lastly, when using a POC HbAlcdevice patients benefit by learning the result during the medical consultation which improves the likelihood of receiving immediate glycemicspecific medical attention. ${ }^{15-17}$ Although these advantages should be balanced by greater cost and the incomplete correlation between $\mathrm{HbAlc}$ and average glucose in certain individuals, ${ }^{18}$ when presented as a POC device, the application to clinical practice is profound allowing for on-the-spot practitioner-guided assessment and patient counseling.

Several investigations have demonstrated the ability of $\mathrm{HbA} 1 \mathrm{c}$ to predict the development of diabetes. ${ }^{19-21} \mathrm{An} \mathrm{HbAlc}$ between 5 and $5.5 \%$ indicates a $5-15$ year relative risk of $3 \%{ }^{19}-12 \%{ }^{20}$ An $\mathrm{HbA} 1 \mathrm{c}$ between $5.5-6 \%$ indicates a $9-25 \%$ relative risk, and an $\mathrm{HbA} 1 \mathrm{c}$ between $6-6.5 \%$ indicates a $25-50 \%$ relative risk of developing diabetes in 5years. ${ }^{11,18}$ Therefore, the average patient screened in this study whose $\mathrm{HbAlc}$ was below the diagnostic limit has a 9-25\% relative risk of developing type 2 diabetes in 5years. ${ }^{18,21}$

Research has proven that early intervention with behavioral modifications has an impressive impact on delaying the development of diabetes. The Diabetes Prevention Program demonstrated that lifestyle modifications targeted to achieve mild weight loss of $7 \%$ or initiation of metformin reduces the development of type 2 diabetes by $58 \%$ or $31 \%$, respectively when compared to placebo. ${ }^{8}$ Thus, interventions to promote identification and increased awareness of those with prediabetes are needed to encourage adoption of type 2 diabetes prevention strategies, particularly among groups known to be at high-risk. ${ }^{2}$ The current study demonstrated that use of a POC $\mathrm{HbAlc}$ screening test in this high-risk rural population improved the undiagnosed rate of diabetes and especially prediabetes, which can have a significant public health impact through the implementation of pharmaceutical and/or behavioral modifications.

\section{Limitations}

This methodology did not evaluate the undiagnosed incidence of diabetes in the younger at-risk population; however, it did introduce a simple systematic method of evaluating an adult higher-risk population. Future studies should develop similar easily applied methods to identify and screen the younger at-risk population which may include a solely weight-based approach regardless of the presence of additional risk factors or symptoms. In fact, modeling studies suggest that screening beginning as early as age 30years without the presence of risk factors is cost effective. ${ }^{15}$

\section{Conclusion}

Screening adult patients, 45years or older, for diabetes using a convenient POC HbA1c device facilitated the diagnosis and further articulated the incidence of diabetes and prediabetes in a rural Alabama population. In turn these patients can intentionally incorporate behavioral strategies to either delay the diagnosis or slow the progress of diabetes which will improve their morbidity and mortality.

\section{Acknowledgements}

This project was funded through the Diabetes Hands Foundation through the Big Blue Test and was presented in abstract/poster form at the American Diabetes Association 29th Clinical Conference on Diabetes in Marco Island, FL. Special thanks to Meg Sheppard, PhD, University of Alabama Institute for Rural Health Research for her support in developing the data collection form, and Larry Skelton, MD for welcoming this project into his rural family medicine clinic in Moundville, Alabama.

\section{Conflict of interest}

Author declares that there is no conflict of interest.

\section{References}

1. Centers for Disease Control and Prevention (CDCP). National diabetes statistics report, 2014: Estimates of diabetes and its burden in the United States. Atlanta, Georgia: Department of Health and Human Services, Centers for Disease Control and Prevention. 2014.

2. Li YF, Geiss LS, Burrows NR, et al. Awareness of prediabetes United States, 2005-2010. Morbidity and Mortality Weekly Report (MMWR). 2013;62(11):209-212. 
3. Geiss LS, Yanfeng Li, Kirtland K, et al. Increasing prevalence of diagnosed diabetes United States and Puerto Rico, 1995-2010. Morbidity and Mortality Weekly Report (MMWR). 201261(45):918-921.

4. Dabney BJ, Gosschalk A, Gamm LD, et al. Diabetes in rural America: A literature review. Rural Healthy People 2010: A companion document to Healthy People. Volume 2. College Station, TX: The Texas A\&M University System Health Science Center, School of Rural Public Health, Southwest Rural Health Research Center. 2010

5. Diabetes Report Card. National Center for Chronic Disease Prevention and Health Promotion, Division of Diabetes Translation. Atlanta, Georgia: Centers for Disease Control and Prevention. 2012.

6. Center for Disease Control and Prevention. Diabetes Public Health Resource. Atlanta, USA; 2014.

7. UK Prospective Diabetes Study Group. Tight blood pressure control and risk of macrovascular and microvascular complications in type 2 diabetes: UKPDS 38. BMJ. 1998;317(7160):703-713.

8. Knowler WC, Barrett-Connor E, Fowler SE, et al. Diabetes Prevention Program Research Group (2002) Reduction in the incidence of type 2 diabetes with lifestyle intervention or metformin. New Engl J Med. 2012;346(6):393-403.

9. Rui Li, Shrestha SS, Lipman R, et al. Centers for Diabetes Control and Prevention. Diabetes Interactive Atlas. 2014.

10. Collins S. Clinical pharmacist counters rural culture of diabetes Pharmacy Today. 2014.

11. Healthy People 2020. 2014.

12. Nathan DM, Turgeon H, Regan S. Relationship between glycated haemoglobin levels and mean glucose levels over time. Diabetologia. 2007;50(11):2239-2244.
13. Nathan DM, Kuenen J, Borg R, et al. A1C Derived average glucose study group. Translating the $\mathrm{A} 1 \mathrm{C}$ assay into estimated average glucose values. Diabetes Care. 2008;31(8):1473-1478.

14. Selvin E, Crainiceanu CM, Brancati FL, et al. Short-term variability in measures of glycemia and implications for the classification of diabetes. Arch Intern Med. 2007;167(14):1545-1551.

15. Bubner TK, Laurence CO, Gialamas A, et al. Effectiveness of point-ofcare testing for therapeutic control of chronic conditions: results from the PoCT in General Practice Trial. Med J Aust. 2009;190(11): 624-626.

16. Cagliero E, Levina EV, Nathan DM. Immediate feedback of HbA1C levels improves glycemic control in type 1 and insulin-treated type 2 diabetic patients. Diabetes Care. 1999;22(11):1785-1789.

17. Ferenczi A, Reddy K, Lorber DL. Effect of immediate hemoglobin A1c results on treatment decisions in office practice. Endocr Pract. 2001;7(2): 85-88.

18. American Diabetes Association. Standards of medical care in diabetes. Diabetes Care. 2014;37(Suppl 1):S14-S80.

19. Pradhan AD, Rifai N, Buring JE, et al. Hemoglobin A1c predicts diabetes but not cardiovascular disease in nondiabetic women. $\mathrm{Am} \mathrm{J} \mathrm{Med}$. 2007;120(8):720-727.

20. Selvin E, Steffes MW, Zhu H, et al. Glycated hemoglobin, diabetes, and cardiovascular risk in nondiabetic adults. $N$ Engl $\mathrm{J} \mathrm{Med}$. 2010;362(9):800-811.

21. Zhang X, Gregg EW, Williamson DF, et al. A1C level and future risk of diabetes: a systematic review. Diabetes Care. 2010;33(7):1665-1673. 